\title{
Risk of perforation during endoscopic submucosal dissection using latest insulation-tipped diathermic knife (IT knife-2)
}

Endoscopic submucosal dissection (ESD) enables en bloc resection of lesions regardless of tumor size or location. The insulation-tipped (IT) diathermic knife (Olympus Medical Systems Corp., Tokyo, Japan) is a proven endoscopic device for ESD [1,2]. ESD gastric perforations using the IT knife usually happen during submucosal dissection [3]. However, we present an ESD perforation case that occurred when an IT knife-2, an improved version of the IT knife [4], was being used for circumferential mucosal incision.

A 59-year-old man presented a superficial depressed-type 20-mm lesion ( $\bullet$ Fig. 1), histologically diagnosed as a well-differentiated adenocarcinoma. Under sedation and following submucosal injection of normal saline solution, an initial incision was performed using a needle knife (Olympus Medical Systems Corp.). After the tip of the IT knife-2 had been inserted into the initial incision ( $\bullet$ Fig. $2 \mathbf{a}$ ), an unexpected perforation occurred during the circumferential mucosal incision ( Fig. 2 b, $\bullet$ Video 1). The resection was discontinued and the perforation was successfully closed using endoscopic clips (๑ Fig. 3).

A recent study evaluated the use of the IT knife-2 over the original IT knife, reporting a significantly shorter operating time with no significant changes in the en bloc resection and complication rates [4]. The addition of a three-pronged blade directly beneath the insulation tip of the IT knife-2 seems to be the reason for an increased cutting ability from a vertical view, an enhanced lateral cutting capability, and a greater facility to hook the tissue edge prior to cutting ( $\odot$ Fig. $4 \mathbf{a}$ and b). However, it is our belief that the perforation reported here would not have occurred if the original IT knife had been used at the time. Therefore, more gentle manipulation than that required with the original IT knife should be adopted during circumferential mucosal incision, especially by endoscopists who are inexperienced in the use of this recently developed device.

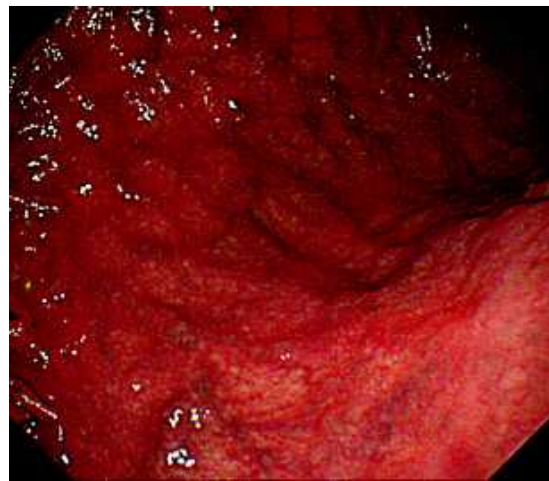

Fig. 1 Endoscopic finding of early gastric cancer. A superficial depressed lesion located in the posterior wall of the lower gastric body was revealed by conventional endoscopy.
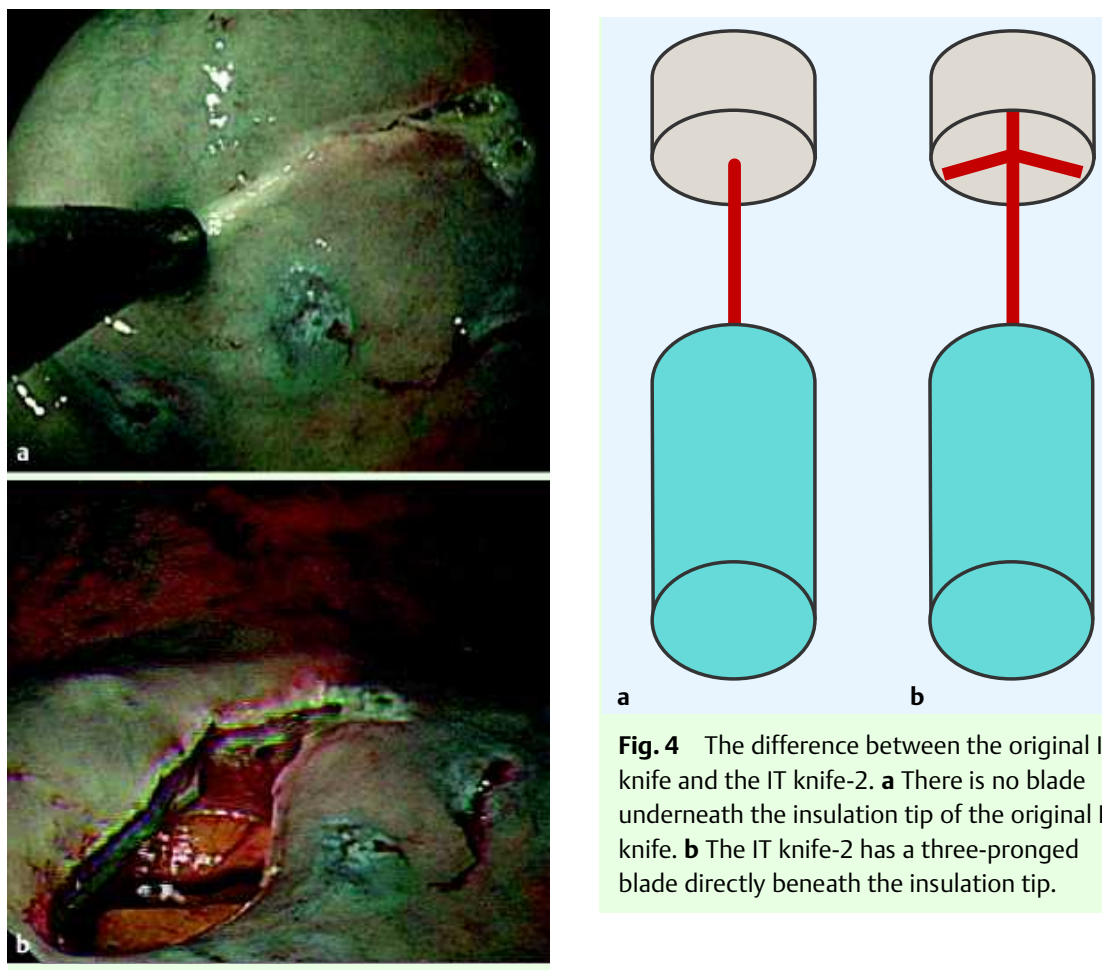

b

Fig. 4 The difference between the original IT knife and the IT knife-2. a There is no blade underneath the insulation tip of the original IT knife. $\mathbf{b}$ The IT knife-2 has a three-pronged blade directly beneath the insulation tip.
Fig. 2 Circumferential mucosal incision. a Circumferential mucosal incision had just begun using the insulation-tipped (IT) knife-2 from the point of small initial incision made with a needle knife. $\mathbf{b}$ Perforation occurred at the beginning of the circumferential mucosal incision. 
S. A. Con ${ }^{1,2}$, I. Oda ${ }^{1}$, H. Suzuki ${ }^{1}$, C. Kusano ${ }^{1}$, S. Kiriyama ${ }^{1}$, T. Gotoda ${ }^{1}$

1 Endoscopy Division, National Cancer Center Hospital, Tokyo, Japan

2 Surgery and Endoscopy Divisions, Centro Digestivo Doctores Con-Mediplaza, San Jose, Costa Rica

\section{References}

1 Hosokawa K, Yoshida S. Recent advances in endoscopic mucosal resection for early gastric cancer. Jpn J Cancer Chemother (English abstract) 1998; 25: 483

2 Gotoda T, Kondo H, Ono H et al. A new endoscopic mucosal resection (EMR) procedure using an insulation-tipped diathermic (IT) knife for rectal flat lesions. Gastrointest Endosc 1999; 50: 560-563

3 Oda I, Ikehara H, Yokoi C et al. How to cope with complication throughout the gastrointestinal tract. In: Conio M, Siersema P, Repici A, Pomchon T (eds). Endoscopic mucosal resection. Oxford, UK: Blackwell Publishing, 2008: $196-211$

4 Ono H, Hasuike N, Inui Tet al. Usefulness of a novel electrosurgical knife, the insulationtipped diathermic knife-2, for endoscopic submucosal dissection of early gastric cancer. Gastric Cancer 2008; 11: 47-52
Bibliography

DOI $10.1055 / \mathrm{s}-0028-1119478$

Endoscopy 2009; 41: E69-E70

(c) Georg Thieme Verlag KG Stuttgart · New York . ISSN 0013-726X

\section{Corresponding author}

\section{Oda, MD}

Endoscopy Division

National Cancer Center Hospital

5-1-1 Tsukiji

Chuo-ku

Tokyo 104-0045

Japan

Fax: +81-3-35423815

ioda@ncc.go.jp 